\title{
A Fast and Automated Strategy for the Identification and Risk Assessment of Unknown Substances (IAS/NIAS) in Plastic Food Contact Materials by GC-Q-Orbitrap HRMS: Recycled LDPE as a Proof-of-Concept
}

\author{
Pablo Miralles ${ }^{1}\left(\mathbb{D}\right.$, Vicent Yusà ${ }^{1,2} \mathbb{D}$, Adriana Pineda ${ }^{3}$ and Clara Coscollà $^{1, *(\mathbb{D})}$ \\ 1 Foundation for the Promotion of Health and Biomedical Research in the Valencian Region (FISABIO-Public \\ Health), Avinguda Catalunya 21, 46020 Valencia, Spain; miralles_pabiba@gva.es (P.M.); \\ yusa_vic@gva.es (V.Y.) \\ 2 Public Health Laboratory of Valencia, Avinguda Catalunya 21, 46020 Valencia, Spain \\ 3 Cadel Deinking S.L., Calle Artesanos 4, 03690 Sant Vicent del Raspeig, Alicante, Spain; \\ adriana.pineda@cadeldeinking.com \\ * Correspondence: coscolla_cla@gva.es; Tel.: +34-961-926-333
}

\section{check for} updates

Citation: Miralles, P.; Yusà, V.; Pineda, A.; Coscollà, C. A Fast and Automated Strategy for the Identification and Risk Assessment of Unknown Substances (IAS/NIAS) in Plastic Food Contact Materials by GC-Q-Orbitrap HRMS: Recycled LDPE as a Proof-of-Concept. Toxics 2021, 9, 283. https://doi.org/ $10.3390 /$ toxics 9110283

Academic Editor: Claudio Medana

Received: 21 September 2021

Accepted: 27 October 2021

Published: 1 November 2021

Publisher's Note: MDPI stays neutral with regard to jurisdictional claims in published maps and institutional affiliations.

Copyright: (c) 2021 by the authors. Licensee MDPI, Basel, Switzerland. This article is an open access article distributed under the terms and conditions of the Creative Commons Attribution (CC BY) license (https:/ / creativecommons.org/licenses/by/ $4.0 /)$.

\begin{abstract}
A fast and automated approach has been developed for the tentative identification and risk assessment of unknown substances in plastic food contact materials (FCM) by GC-Q-Orbitrap HRMS. The proposed approach combines GC-HRMS full scan data acquisition coupled to Compound Discoverer ${ }^{\mathrm{TM}} 3.2$ software for automated data processing and compound identification. To perform the tentative identification of the detected features, a restrictive set of identification criteria was used, including matching with the NIST Mass Spectral Library, exact mass of annotated fragments, and retention index calculation. After the tentative identification, a risk assessment of the identified substances was performed by using the threshold of toxicological concern (TTC) approach. This strategy has been applied to recycled low-density polyethylene (LDPE), which could be used as FCM, as a proof-of-concept demonstration. In the analyzed sample, 374 features were detected, of which 83 were tentatively identified after examination of the identification criteria. Most of these were additives, such as plasticizers, used in a wide variety of plastic applications, oligomers of LDPE, and substances with chemical, industrial, or cosmetic applications. The risk assessment was performed and, according to the TTC approach, the obtained results showed that there was no risk associated with the release of the identified substances. However, complementary studies related to the toxicity of the unidentified substances and the potential mixture toxicity (cocktail effects) should be conducted in parallel using bioassays.
\end{abstract}

Keywords: food contact materials; gas chromatography; high-resolution mass spectrometry; lowdensity polyethylene; non-intentionally added substances; untargeted analysis

\section{Introduction}

In Europe, plastic materials and articles intended to come into contact with food should comply with the Commission Regulation (EU) No 10/2011 [1], which contains the 'Union list of authorized monomers, other starting substances, macromolecules obtained from microbial fermentation, additives and polymer production aids' (intentionally added substances, IAS) that can be used for the manufacture of plastic FCM [1]. Moreover, overall and specific migration limits (SML) have also been established [1]. However, during the manufacturing processes and uses of plastic FCM, the reaction and degradation of products can occur (non-intentionally added substances, NIAS). For this reason, the risk associated with the presence and potential release of NIAS should be assessed before the authorization of FCM [2]. 
In this sense, the non-target analysis of unknown compounds (IAS/NIAS) in plastic FCM is an analytical field that has gained popularity during the last few years [3,4], as demonstrated by the several review articles published recently on this topic [5-10].

Regarding the most common analytical techniques, most of the published papers dealing with the non-target analysis of plastic FCM are based on liquid chromatography (LC) coupled to high-resolution mass spectrometry (HRMS) using hybrid mass analyzers, such as quadrupole-time-of-flight (Q-TOF) [11,12] or Q-Orbitrap [4,13-16]. In this regard, low-energy ionization sources, such as electrospray ionization (ESI), allow observation of the molecular ion, thus easing significantly the identification of substances.

If these analyzers are not used, then published papers that used gas chromatography (GC) coupled to mass spectrometry (MS) usually required tedious and time consuming manual processing of the acquired data in order to perform the identification of the unknown substances [12,17-20], even being necessary to compare the MS spectra of the acquired peaks one by one with those included in the NIST Mass Spectral Library [21]. In this regard, comprehensive two-dimensional gas chromatography $(\mathrm{GC} \times \mathrm{GC})$ can also be a useful technique in order to improve the characterization power of GC separations [22].

In general terms, non-target GC analysis enables the characterization of the less polar and more volatile migrant substances, while LC is more suitable for the analysis of polar and non-volatile migrant substances [12,17]. In this respect, the deconvolution of electron ionization (EI) spectra and automated substance identification are major challenges for non-target GC analysis. With regard to MS detectors coupled to GC, most of the published papers have used low-resolution MS [12,20,23-26], and only a few of them used HRMS detectors, mainly Q-TOF [11,18,27,28] and, less frequently, Orbitrap [19]. In this regard, HRMS offers broad advantages over low-resolution MS for the identification of unknown substances as the molecular formula of the acquired ions can be reliably obtained from their exact mass, thus easing their characterization [29].

After the unknown substances have been detected and tentatively identified, it is necessary to perform a risk assessment to evaluate the safety of the plastic FCM. For substances with no toxicological data available, the threshold of toxicological concern (TTC) approach based on Cramer rules [30-32] was applied using Toxtree software [33]. According to Commission Regulation (EU) No 10/2011, NIAS should not migrate into food or food simulants in levels higher than $0.01 \mathrm{mg} \mathrm{kg}^{-1}$, except for substances whose genotoxicity has not been discarded, which should not migrate in levels higher than $0.00015 \mathrm{mg} \mathrm{kg}^{-1}$ [1]. Moreover, for authorized substances (IAS) according to Commission Regulation (EU) No 10/2011 [1], SML were considered.

According to the European Commission, the demand for recycled plastics is only about the $6 \%$ of the total plastic consumption in Europe [34]. The massive production, use, and disposal of plastic packaging are generating enormous amounts of waste and contributing to environmental problems of great concern. For this reason, the research and development of new FCM based on recycled plastic is a matter of interest and an economic field with great potential for plastic and packaging industries.

Among recycled plastic materials, recycled low-density polyethylene (LDPE) is one of the most demanded in a wide variety of applications that require flexible materials, such as carrier bags or shrink and stretch films [35]. However, post-consumer LDPE may contain residues and contaminants from previous uses, non-authorized substances, or substances from non-food applications. For this reason, an exhaustive evaluation of migrant substances, both IAS and NIAS, is necessary in order to ensure the safety of recycled LDPE $[1,4,36]$. In Europe, recycled plastic FCM need to be manufactured according to recycling processes previously authorized by the European Food Safety Authority (EFSA), in order to ensure that the plastic input originates from plastic materials and articles that have been manufactured in accordance with EU legislation on plastic food contact materials and articles, and that the recycling process eliminates contamination or reduces it to a concentration that does not pose a risk to human health $[2,34,36]$. 
The non-target analysis of recycled LDPE, which could be used as FCM, has only been previously considered by our research group, using an LC-HRMS approach [4]. In this sense, the present study constitutes a novel and complementary methodology to perform the identification and risk assessment of the more volatile and less polar migrant substances, which could not be identified with the previously addressed LC approach [4].

To the best of our knowledge, this is the first study addressing a reliable and automated methodology to perform the identification and risk assessment of unknown substances (IAS/NIAS) in recycled LDPE, which could be used as FCM, by GC-Q-Orbitrap HRMS.

\section{Materials and Methods}

\subsection{Reagents and Samples}

Analytical standards of Benzophenone (CAS 119-61-9), Butyl stearate (CAS 123-95-5), Diisobutyl phthalate (CAS 84-69-5), and Tris (2,4-di-tert-butylphenyl) phosphite (Irgafos 168, CAS 31570-04-4), from LGC Standards (Bury, United Kingdom), and Bis (2-ethylhexyl) adipate (CAS 103-23-1), Bis (2-ethylhexyl) phthalate (CAS 117-81-7), Bis (2-ethylhexyl) terephthalate (CAS 6422-86-2), Butylated hydroxytoluene (CAS 128-37-0), Diphenyl sulphone (CAS 127-63-9), and Tri-n-butyl acetyl citrate (CAS 77-90-7), from Merck KGaA (Darmstadt, Germany), were used as standards for confirmation and quantification.

Analytical standards of Phenol-13C6 (CAS 89059-34-7), Benzophenone-D10 (CAS 22583-75-1), and Bis (2-ethylhexyl) phthalate-D4 (CAS 93951-87-2), all from LGC Standards (Bury, UK), were used as internal standards.

Standard n-alkane mixtures, C8-C20 and C10-C40 (all even), both from Merck KGaA (Darmstadt, Germany), were used for retention index calculation.

Acetone $\geq 99.8 \%$, residue-analysis grade, from VWR International (Radnor, PA, USA), was used as solvent.

The analyzed sample was a post-consumer recycled LDPE film provided by Cadel Deinking, S.L. (Sant Vicent del Raspeig, Spain). The recycled LDPE film was obtained through a patented process that uses water-based chemicals to remove contaminants and includes grinding, washing, drying, and extrusion [37].

\subsection{Analytical Strategy}

The developed analytical strategy, which includes solvent extraction of the plastic FCM, GC-HRMS analysis, automated data processing, and tentative compound identification, is depicted in Figure 1.

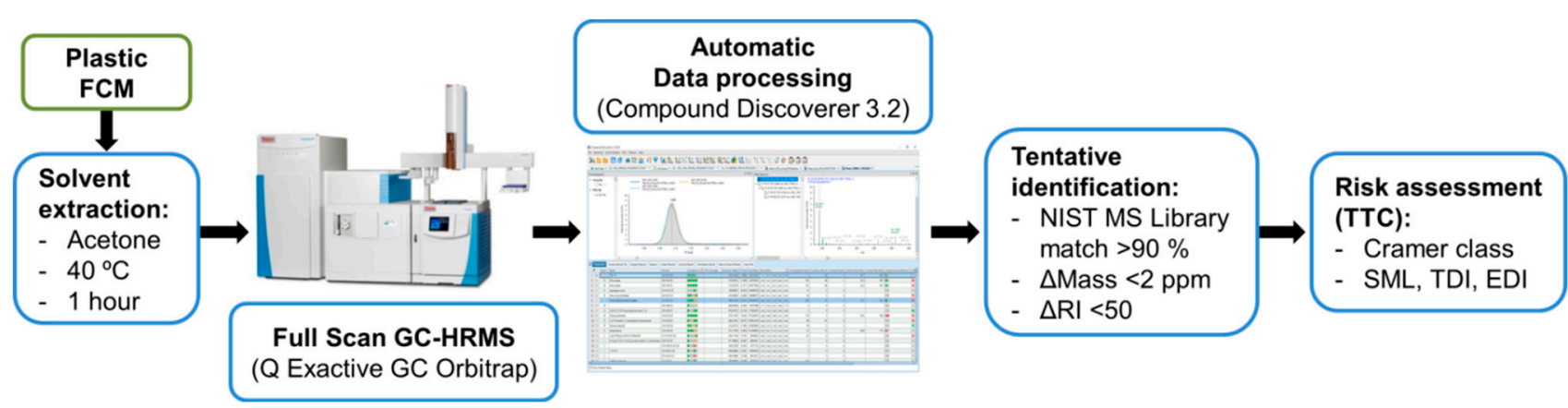

Figure 1. Scheme of the overall analytical methodology.

\subsubsection{Sample Preparation and Solvent Extraction}

The recycled LDPE sample was extracted with an organic solvent in order to release the contaminants from the polymeric matrix. In this case, acetone was selected as extraction solvent to simulate the migration of unknown substances (IAS/NIAS). According to Commission Regulation (EU) No 10/2011 [1], migration tests should be performed using food simulants under standardized conditions. With regard to the food simulants described in Commission Regulation (EU) No 10/2011 [1], in the case of aqueous and hydrophilic 
foods, ethanol-water mixtures, i.e., food simulants $A, C$, and D1 (with an ethanol content of 10,20 , and $50 \% v / v$, respectively), and food simulant B (acetic acid $3 \%, w / v$ ), in the case of acid foods, are proposed to perform migration tests. In the case of fatty foods, the regulated food simulants are vegetable oil (food simulant D2) or alternative food simulants, such as ethanol $95 \%$ or iso-octane. However, a direct extraction of the plastic sample with an organic solvent was preferred as a faster and more extractive procedure. Among the different organic solvents that could be used for this purpose, acetone was selected due to its high volatility and low boiling point $\left(56^{\circ} \mathrm{C}\right)$, it being a suitable solvent for direct injection into the GC system, its moderate polarity (2.69 D), it being able to extract a wide range of polar and non-polar substances, and its low toxicity, compared to other possible organic solvents, such as n-hexane or dichloromethane.

Compared to the regulated food simulants, acetone presents a higher extraction capability than ethanol-water mixtures in order to extract both polar and non-polar compounds, and it is similar to the alternative food simulants for fatty foods with regard to the extraction of less polar substances. For that reason, acetone was selected as a compromise situation to cover any possible application of the recycled FCM, for both aqueous and/or fatty foods. With regard to test conditions, $1 \mathrm{~h}$ of extraction time was selected as a faster approach compared to the standardized conditions of Commission Regulation (EU) No $10 / 2011$ [1], which usually range from $24 \mathrm{~h}$ to 10 days.

By triplicate, a portion of $5 \mathrm{~cm} \times 5 \mathrm{~cm}\left(0.25 \mathrm{dm}^{2}\right)$ of the recycled LDPE film was introduced in a $50 \mathrm{~mL}$ glass beaker with $20 \mathrm{~mL}$ of acetone and kept in an oven at $40{ }^{\circ} \mathrm{C}$ for $1 \mathrm{~h}$. The beaker was sealed with aluminum foil to prevent solvent evaporation. After that, the whole sample extract was collected using only glassware material and it was evaporated under gently nitrogen stream to $0.5 \mathrm{~mL}$. Then, the concentrated extract was transferred to a $1 \mathrm{~mL}$ volumetric flask, spiked with $200 \mathrm{ng} \mathrm{mL}^{-1}$ of the internal standards, and filled up to the line using the same solvent. Finally, the sample extract was placed into an injection vial for GC analysis. Additionally, an extraction blank was prepared by triplicate following the same procedure, leaving out the recycled LDPE sample. In order to prevent contamination from the laboratory environment, all the glassware materials were rinsed with acetone and drained before their use.

\subsubsection{GC-HRMS Analysis}

A Trace 1310 GC system equipped with a TraceGOLD TG-5MS column $(30 \mathrm{~m}, 0.25 \mathrm{~mm}$, $0.25 \mu \mathrm{m}$ ), coupled to a Q-Exactive GC Orbitrap HRMS detector, all from Thermo Fisher Scientific (Waltham, MA, USA), were used. The injection volume was $1 \mu \mathrm{L}$ (splitless mode) and the inlet was set at $280^{\circ} \mathrm{C}$. The GC operated in constant flow mode at $1.2 \mathrm{~mL} \mathrm{~min}^{-1}$ of helium as carrier gas, using the following oven temperature program: $40^{\circ} \mathrm{C}$, held for $5 \mathrm{~min} ; 5^{\circ} \mathrm{C} \mathrm{min}^{-1}$ up to $315^{\circ} \mathrm{C}$, held for $10 \mathrm{~min}$. The MS transfer line was set at $300^{\circ} \mathrm{C}$. The EI ion source operated at $70 \mathrm{eV}$, and the ion source temperature was set at $250{ }^{\circ} \mathrm{C}$. The acquisition was performed in full scan mode with a resolving power of 60,000 FWHM and a mass range from 40 to $500 \mathrm{~m} / \mathrm{z}$.

To perform retention index (RI) calculation, standard n-alkane mixtures, C8-C20 and C10-C40 (all even), were injected with the same conditions.

\subsubsection{Data Processing for Tentative Identification}

In order to perform the tentative identification of the acquired features, the obtained data were processed automatically using the software Compound Discoverer ${ }^{\mathrm{TM}} 3.2(\mathrm{CD}$ 3.2) [38], from Thermo Fisher Scientific (Waltham, MA, USA). Briefly, the automatic data processing workflow performed alignment of retention time, deconvolution of EI spectra, unknown compound identification, and removal of background features. CD 3.2 automatically identifies substances using NIST Mass Spectral Library [21] and local database Mass Lists searches (in the present study, the 'Extractable and Leachable HRMS database' containing 1741 compounds, the 'GC Orbitrap Contaminants library' containing 880 compounds, the 'GC Orbitrap Flavor and Fragrance database' containing 49 compounds, the 'GC Or- 
bitrap Metabolomics library' containing 1014 compounds, and a home-made database containing 674 plastic-related substances).

For the tentative identification of the acquired features, a restrictive set of identification criteria, including EI spectra match with NIST Mass Spectral Library, exact mass of annotated fragments, and retention index (RI), was used. These parameters are shown in Table 1.

Table 1. Criteria used for the tentative identification of unknown substances.

\begin{tabular}{|c|c|}
\hline Parameter & Criteria \\
\hline NIST MS Library match (Total score) ${ }^{1}$ & $>90 \%$ \\
\hline Exact mass accuracy $(\Delta \text { Mass })^{2}$ & $<2 \mathrm{ppm}$ \\
\hline Retention index absolute difference $(\Delta \mathrm{RI})^{3}$ & $<50$ units \\
\hline
\end{tabular}

${ }^{1}$ Match between deconvoluted EI spectrum and NIST Mass Spectral Library [21]. Total score is a composite metric that includes contribution from the High resolution filtering score (HRF) and the Search index (SI) score. ${ }^{2}$ Exact mass accuracy ( $\triangle$ Mass) for at least 3 annotated fragments or 2 fragments and molecular ion, when observed. ${ }^{3}$ Retention index absolute difference $(\Delta \mathrm{RI})$ between calculated RI and NIST library RI.

As can be seen, in order to consider a proposed substance by CD 3.2 as tentatively identified, a positive match (Total score) > 90\% with NIST Mass Spectral Library was required. 'Total score' is a composite metric that includes contribution from the 'High resolution filtering score' (HRF) and the 'Search index' (SI) score. According to this, a higher 'Total score' implies a higher probability of a positive match for a proposed substance. In addition to that, an exact mass accuracy $(\Delta$ Mass $)<2$ ppm for at least 3 annotated fragments (matching fragment ions between acquired spectrum and NIST library spectrum), or 2 fragments and the molecular ion, if observed, was also required. With regard to retention index $(\mathrm{RI})$, an absolute difference $(\Delta \mathrm{RI})<50$ units between calculated RI and NIST library RI (column type: semi standard non polar) was required. In cases where the RI value was not available in the NIST library for the proposed substances, the most probable compound according to the abovementioned criteria was considered. All these parameters were calculated and provided automatically by CD 3.2 software.

Moreover, CD 3.2 also performed searches on local database Mass Lists, which include structure, molecular formula, and exact mass of substances. Despite EI spectra not being included in Mass Lists, they are useful to increase the confidence of the tentative identification if a positive match with a Mass List is obtained and the molecular ion of the proposed substance is also observed.

\subsection{Risk Assessment}

To perform the risk assessment of the released substances, the threshold of toxicological concern (TTC) approach was applied by using the Toxtree software [33]. This approach estimates the tolerable daily intake (TDI, mg person ${ }^{-1}$ day $^{-1}$ ) for a given substance through the Cramer decision rules, according to molecular structure, which assign each substance into one Cramer class of toxicological hazard: Class I (Low hazard), $1.80 \mathrm{mg}_{\text {person }}{ }^{-1}$ day $^{-1}$; Class II (Intermediate hazard), $0.54 \mathrm{mg}_{\text {person }}{ }^{-1}$ day $^{-1}$; Class III (High hazard), $0.09 \mathrm{mg}_{\text {person }}{ }^{-1} \mathrm{day}^{-1}$. After that, TDI values were compared with the estimated daily intake (EDI, mg person ${ }^{-1}$ day $^{-1}$ ), calculated considering the current European default assumption that a reference adult person consumes one kilogram of packed food per day [39], according to the following expression: EDI (mg person ${ }^{-1} \mathrm{day}^{-1}$ ) $=$ Migration $\left(\mathrm{mg} \mathrm{kg}^{-1}\right) \times 1 \mathrm{~kg}$ (daily intake of packed food). Migration $\left(\mathrm{mg} \mathrm{kg}^{-1}\right)$ was estimated considering the average response factor of internal standards [2]. The average response factor of internal standards was obtained as the average ratio between the peak area of the internal standard and its known added concentration. From that, the estimated concentrations of unknown substances were obtained as the ratio between their peak area and the average response factor. In order to express the values of estimated migration in $\mathrm{mg} \mathrm{kg}^{-1}$, the conventional food contact surface ratio of $6 \mathrm{dm}^{2}$ per $\mathrm{kg}$ of food was considered [1]. 
According to Commission Regulation (EU) No 10/2011 [1], a maximum limit of $0.01 \mathrm{mg} \mathrm{kg}^{-1}$ is established for the migration of NIAS from FCM across a functional barrier. In the case of substances for which genotoxicity has not been discarded, a maximum limit of $0.00015 \mathrm{mg} \mathrm{kg}^{-1}$ is applicable [1]. For this reason, only the identified substances with an estimated migration over $0.00015 \mathrm{mg} \mathrm{kg}^{-1}$ were considered for the risk assessment.

\section{Results and Discussion}

\subsection{System Suitability}

In order to evaluate the system suitability of the GC-HRMS analysis, a standard solution containing $200 \mathrm{ng} \mathrm{mL}^{-1}$ of the internal standards was analyzed in triplicate before and after the acquisition workflow. The system suitability was evaluated in terms of relative standard deviation (RSD, \%) of base peak area and retention time, and mass accuracy ( $\triangle$ Mass, ppm) of the internal standards. The RSD of base peak area ranged from 2.4 to $8.3 \%$, and RSD of retention time ranged from 0.02 to $0.1 \%$. Mass accuracy ranged from -0.13 to $0.74 \mathrm{ppm}$, thus showing that the allowed mass accuracy of $2 \mathrm{ppm}$ for the identification criteria (see Table 1) is wider enough to avoid false negatives. These results show that the GC-HRMS system operated steadily and accurately during the analytical sequence.

\subsection{Identification of Unknown Substances}

After the recycled LDPE sample was analyzed in triplicate, the acquired data were processed using CD 3.2 as specified above (see Section 2.2.3). The software automatically annotated 374 features, of which 83 compounds could be tentatively identified after examination of the identification criteria (see Table 1). The 83 identified substances are shown in Table 2. It is necessary to consider that the post-consumer recycled LDPE could present contaminants from a wide variety of sources, such as residues from previous uses, or reaction and degradation products during the manufacture and recycling processes.

Table 2. Tentatively identified substances in the analyzed recycled LDPE sample.

\begin{tabular}{|c|c|c|c|c|}
\hline Compound Name ${ }^{1}$ & CAS Number & $\begin{array}{l}\text { Molecular } \\
\text { Formula }\end{array}$ & $\begin{array}{c}\text { NIST Match } \\
\text { (Total Score, \%) }\end{array}$ & $\begin{array}{c}\Delta \mathrm{RI} \\
\text { (a.u.) }^{3}\end{array}$ \\
\hline \multicolumn{5}{|c|}{ Acetate esters } \\
\hline $\begin{array}{l}\text { 7-Tetradecen-1-yl } \\
\text { acetate }\end{array}$ & $16974-10-0$ & С16 H30 O2 & 93.2 & 24 \\
\hline Hexadecyl acetate & $629-70-9$ & C18 H36 O2 & 93.5 & 3 \\
\hline $\begin{array}{c}\text { Hexadecyl } \\
\text { trifluoroacetate }\end{array}$ & $6222-03-3$ & C18 H33 F3 O2 & 95.9 & 20 \\
\hline $\begin{array}{l}\text { Octadecyl } \\
\text { trifluoroacetate }\end{array}$ & $79392-43-1$ & C20 H37 F3 O2 & 95.6 & 14 \\
\hline $\begin{array}{c}\text { Tri-n-butyl acetyl } \\
\text { citrate * }\end{array}$ & $77-90-7$ & C20 H34 O8 & 95.7 & 4 \\
\hline \multicolumn{5}{|c|}{ Aldehydes and ketones } \\
\hline Benzophenone * & $119-61-9$ & $\mathrm{C} 13 \mathrm{H} 10 \mathrm{O}$ & 95.8 & 8 \\
\hline $\begin{array}{l}\text { 2,6-Di-tert-butyl-1,4- } \\
\text { benzoquinone }\end{array}$ & $719-22-2$ & C14 H20 O2 & 94.9 & 10 \\
\hline $\begin{array}{c}\text { 3,5-Di-tert-butyl-4- } \\
\text { hydroxybenzaldehyde }\end{array}$ & $1620-98-0$ & $\mathrm{C} 15 \mathrm{H} 22 \mathrm{O} 2$ & 96.1 & 17 \\
\hline $\begin{array}{l}\text { 7,9-Di-tert-butyl-1- } \\
\text { oxaspiro(4,5)deca-6,9- } \\
\text { diene-2,8-dione }\end{array}$ & $82304-66-3$ & C17 H24 O3 & 96.1 & 21 \\
\hline $\begin{array}{l}\text { Dehydroabietic } \\
\text { aldehyde }\end{array}$ & $13601-88-2$ & C20 H28 O & 96.4 & 1 \\
\hline
\end{tabular}


Table 2. Cont.

\begin{tabular}{|c|c|c|c|c|}
\hline Compound Name ${ }^{1}$ & CAS Number & $\begin{array}{l}\text { Molecular } \\
\text { Formula }\end{array}$ & $\begin{array}{c}\text { NIST Match } \\
(\text { Total Score, } \%)^{2}\end{array}$ & $\begin{array}{c}\Delta \mathrm{RI} \\
\text { (a.u.) }^{3}\end{array}$ \\
\hline \multicolumn{5}{|c|}{ Alkenes } \\
\hline 1-Hexadecene & $629-73-2$ & C16 H32 & 96.5 & 1 \\
\hline 9-Nonadecene & $31035-07-1$ & C19 H38 & 91.4 & 29 \\
\hline 1-Docosene & $1599-67-3$ & $\mathrm{C} 22 \mathrm{H} 44$ & 91.3 & 50 \\
\hline 9-Tricosene & 27519-02-4 & $\mathrm{C} 23 \mathrm{H} 46$ & 93.5 & 3 \\
\hline 1-Tetracosene & $10192-32-2$ & $\mathrm{C} 24 \mathrm{H} 48$ & 95.3 & 0 \\
\hline 1-Hexacosene & $18835-33-1$ & C26 H52 & 93.7 & 2 \\
\hline Squalene & $111-02-4$ & C $30 \mathrm{H} 50$ & 96.4 & 0 \\
\hline \multicolumn{5}{|c|}{ Phenol derivatives } \\
\hline 1,2-Diphenoxyethane & $104-66-5$ & C14 H14 O2 & 97.5 & 10 \\
\hline 2,4-Di-tert-butylphenol & $96-76-4$ & $\mathrm{C} 14 \mathrm{H}_{22} \mathrm{O}$ & 97.2 & 12 \\
\hline 2,6-Di-tert-butylphenol & $128-39-2$ & $\mathrm{C} 14 \mathrm{H} 22 \mathrm{O}$ & 96.8 & 10 \\
\hline $\begin{array}{c}\text { Butylated } \\
\text { hydroxytoluene * }\end{array}$ & $128-37-0$ & C15 H24 O & 97.0 & 9 \\
\hline $\begin{array}{l}\text { 2,4-Di-tert- } \\
\text { pentylphenol }\end{array}$ & $120-95-6$ & $\mathrm{C} 16 \mathrm{H} 26 \mathrm{O}$ & 92.6 & 38 \\
\hline Metilox & $6386-38-5$ & $\mathrm{C} 18 \mathrm{H} 28 \mathrm{O} 3$ & 94.7 & 16 \\
\hline Irganox $1076^{*}$ & $2082-79-3$ & $\mathrm{C} 35 \mathrm{H} 62 \mathrm{O} 3$ & 93.0 & 8 \\
\hline \multicolumn{5}{|c|}{ Phthalates } \\
\hline Dibutyl phthalate* & $84-74-2$ & $\mathrm{C} 16 \mathrm{H} 22 \mathrm{O} 4$ & 94.6 & 2 \\
\hline Diisobutyl phthalate & $84-69-5$ & C16 H22 O4 & 96.4 & 13 \\
\hline $\begin{array}{l}\text { Bis(2-ethylhexyl) } \\
\text { phthalate * }\end{array}$ & $117-81-7$ & $\mathrm{C} 24 \mathrm{H} 38 \mathrm{O} 4$ & 98.2 & 2 \\
\hline $\begin{array}{l}\text { Bis(2-ethylhexyl) } \\
\text { terephthalate * }\end{array}$ & $6422-86-2$ & C24 H38 O4 & 94.7 & 28 \\
\hline \multicolumn{5}{|c|}{ Primary alcohols } \\
\hline 3-Nonenol & $10340-23-5$ & C9 H18 O & 95.7 & 48 \\
\hline Octadecanol & $112-92-5$ & C18 H38 O & 96.2 & 3 \\
\hline Nonadecanol & $1454-84-8$ & $\mathrm{C} 19 \mathrm{H} 40 \mathrm{O}$ & 96.3 & 18 \\
\hline Eicosanol & $629-96-9$ & $\mathrm{C} 20 \mathrm{H} 42 \mathrm{O}$ & 90.9 & 20 \\
\hline Docosanol & $661-19-8$ & $\mathrm{C} 22 \mathrm{H} 46 \mathrm{O}$ & 90.4 & 12 \\
\hline Tetracosanol & $506-51-4$ & C24 H50 O & 86.2 & 11 \\
\hline \multicolumn{5}{|c|}{ Cyclic and aromatic hydrocarbons } \\
\hline $\begin{array}{c}2,6- \\
\text { Diisopropylnaphthalene } \\
2,2^{\prime}, 5,5^{\prime} \text {-Tetramethyl- }\end{array}$ & 24157-81-1 & C16 H20 & 96.7 & 8 \\
\hline $\begin{array}{c}1,1^{\prime}- \\
\text { biphenyl }\end{array}$ & $3075-84-1$ & C16 H18 & 94.2 & 42 \\
\hline Undecylcyclohexane & $54105-66-7$ & C17 H34 & 94.6 & 3 \\
\hline 1-Ethyldecylbenzene & $2400-00-2$ & С18 H30 & 90.3 & 1 \\
\hline $\begin{array}{c}\text { 7-Isopropyl-1-methyl- } \\
\text { 1,2,3,4- } \\
\text { tetrahydrophenanthrene } \\
\text { 7-Isopropyl-1,4- }\end{array}$ & $6566-19-4$ & C18 H22 & 96.2 & 11 \\
\hline $\begin{array}{l}\text { dimethyl } \\
\text { tetradecahydrophenanthrene }\end{array}$ & $2221-95-6$ & С19 Н34 & 96.7 & 9 \\
\hline m-Camphorene & 20016-73-3 & $\mathrm{C} 20 \mathrm{H} 32$ & 92.6 & 44 \\
\hline $\begin{array}{c}1,3,5- \\
\text { Triphenylcyclohexane }\end{array}$ & $28336-57-4$ & $\mathrm{C} 24 \mathrm{H} 24$ & 95.3 & 31 \\
\hline
\end{tabular}


Table 2. Cont.

\begin{tabular}{|c|c|c|c|c|}
\hline Compound Name ${ }^{1}$ & CAS Number & $\begin{array}{l}\text { Molecular } \\
\text { Formula }\end{array}$ & $\begin{array}{c}\text { NIST Match } \\
(\text { Total Score, \%) }\end{array}$ & $\begin{array}{c}\Delta \mathrm{RI} \\
\text { (a.u.) }^{3}\end{array}$ \\
\hline \multicolumn{5}{|c|}{ Fatty acid methyl esters (FAMEs) } \\
\hline Methyl laurate & $111-82-0$ & C13 H26 O2 & 95.8 & 13 \\
\hline Methyl palmitate & $112-39-0$ & C17 H34 O2 & 97.7 & 16 \\
\hline Methyl heptadecanoate & $1731-92-6$ & $\mathrm{C} 18 \mathrm{H} 36 \mathrm{O} 2$ & 94.2 & 11 \\
\hline Methyl linolelaidate & $2566-97-4$ & C19 H34 O2 & 98.0 & 20 \\
\hline Methyl elaidate & $1937-62-8$ & $\mathrm{C} 19 \mathrm{H} 36 \mathrm{O} 2$ & 98.1 & 4 \\
\hline Methyl stearate & $112-61-8$ & C19 H38 O2 & 97.8 & 12 \\
\hline Methyl erucate & $1120-34-9$ & $\mathrm{C} 23 \mathrm{H} 44 \mathrm{O} 2$ & 91.8 & 0 \\
\hline Methyl isopimarate & $1686-62-0$ & C21 H32 O2 & 92.1 & 1 \\
\hline Methyl icosanoate & $1120-28-1$ & C21 H42 O2 & 97.2 & 13 \\
\hline \multicolumn{5}{|c|}{ Other fatty acid esters (FAEs) } \\
\hline Isopropyl myristate & $110-27-0$ & C17 H34 O2 & 94.3 & 4 \\
\hline Ethyl palmitate & $628-97-7$ & C18 H36 O2 & 92.1 & 1 \\
\hline Butyl palmitate * & $111-06-8$ & C20 H40 O2 & 93.1 & 4 \\
\hline Butyl stearate * & $123-95-5$ & $\mathrm{C} 22 \mathrm{H} 44 \mathrm{O} 2$ & 94.3 & 3 \\
\hline Hexadecyl palmitate & $540-10-3$ & C32 H64 O2 & 95.0 & 0 \\
\hline \multicolumn{5}{|c|}{ Linear and branched polyethylene oligomers } \\
\hline Tetradecane & $629-59-4$ & C14 H30 & 96.5 & 0 \\
\hline Hexadecane & $544-76-3$ & C16 H34 & 96.7 & 0 \\
\hline Heptadecane & $629-78-7$ & C17 H36 & 96.9 & 2 \\
\hline Octadecane & $593-45-3$ & С18 H38 & 96.6 & 0 \\
\hline Eicosane & $112-95-8$ & C20 H42 & 96.5 & 0 \\
\hline Tetracosane & $646-31-1$ & C24 H50 & 95.7 & 0 \\
\hline Pentacosane & $629-99-2$ & C25 H52 & 94.0 & 31 \\
\hline Heptacosane & $593-49-7$ & C27 H56 & 94.4 & 2 \\
\hline Octacosane & $630-02-4$ & C28 H58 & 96.1 & 0 \\
\hline Tetraiacontane & $14167-59-0$ & C34 H70 & 92.1 & 0 \\
\hline 3-Methylpentadecane & $2882-96-4$ & C16 H34 & 93.1 & 1 \\
\hline 3-Methylheptadecane & $6418-44-6$ & С18 H38 & 94.9 & 2 \\
\hline 3-Methylnonadecane & $6418-45-7$ & C20 H42 & 95.5 & 2 \\
\hline $\begin{array}{c}\text { 2,6,10,15-Tetramethyl } \\
\text { heptadecane }\end{array}$ & $54833-48-6$ & C21 H44 & 92.3 & 30 \\
\hline 3-Methylheneicosane & $6418-47-9$ & C22 H46 & 95.9 & 1 \\
\hline 5-Methylheneicosane & $25117-37-7$ & $\mathrm{C} 22 \mathrm{H} 46$ & 95.5 & 1 \\
\hline 11-Methyltricosane & $27538-41-6$ & C24 H50 & 95.3 & 38 \\
\hline 2-Methyloctacosane & $1560-98-1$ & C29 H60 & 95.7 & 43 \\
\hline 5-Methylnonacosane & $71868-29-6$ & C30 H62 & 94.1 & 9 \\
\hline \multicolumn{5}{|c|}{ Other compounds } \\
\hline Diphenyl sulphone * & $127-63-9$ & $\mathrm{C} 12 \mathrm{H} 10 \mathrm{O} 2 \mathrm{~S}$ & 93.0 & - \\
\hline 1-Chlorohexadecane & $4860-03-1$ & C16 H33 Cl & 94.2 & 21 \\
\hline $\begin{array}{c}\mathrm{N}, \mathrm{N}- \\
\text { Dimethylpalmitylamine }\end{array}$ & $112-69-6$ & C18 H39 N & 96.1 & - \\
\hline Galaxolide & $1222-05-5$ & $\mathrm{C} 18 \mathrm{H} 26 \mathrm{O}$ & 95.8 & - \\
\hline $\begin{array}{c}\text { Methyl } \\
\text { dehydroabietate }\end{array}$ & $1235-74-1$ & C21 H30 O2 & 97.6 & 2 \\
\hline Methyl abietate & $127-25-3$ & C21 H32 O2 & 96.2 & 4 \\
\hline $\begin{array}{l}\text { Bis(2-ethylhexyl) } \\
\text { adipate * }\end{array}$ & $103-23-1$ & $\mathrm{C} 22 \mathrm{H} 42 \mathrm{O} 4$ & 93.5 & 12 \\
\hline Irgafos $168 *$ & $31570-04-4$ & C42 H63 O3 P & 94.7 & 5 \\
\hline
\end{tabular}

${ }^{1}$ All compounds presented an exact mass accuracy ( $\Delta$ Mass) $<2$ ppm for at least 3 fragment ions, or 2 fragments and molecular ion. ${ }^{2}$ Exact mass accuracy ( $\triangle$ Mass) for at least 3 annotated fragments or 2 fragments and molecular ion, when observed. ${ }^{3}$ Retention index absolute difference $(\Delta \mathrm{RI})$ between calculated RI and NIST library RI. * Authorized substances (IAS) according to Commission Regulation (EU) No $10 / 2011[1]$. 
As stated above, all compounds presented a positive match (Total score) $>90 \%$ with NIST Mass Spectral Library [21], an exact mass accuracy ( $\Delta$ Mass) $<2$ ppm for at least 3 annotated fragments, or 2 fragments and the molecular ion, if observed, and an absolute RI difference $(\Delta \mathrm{RI})<50$ units between calculated RI and NIST library RI, if available.

Out of 83 tentatively identified substances, only 12 are included in the 'Union list of authorized substances' (IAS) of Commission Regulation 10/2011 [1]. As can be seen, most of the identified substances were polymer additives, such as plasticizers, surfactants, stabilizers, or emulsifiers. Moreover, some metabolites and substances with a wide variety of industrial, chemical, and cosmetic applications were also identified. In addition to that, different linear and branched polyethylene oligomers $\left(\mathrm{C}_{n} \mathrm{H}_{2 n+2}\right)$ were found in the analyzed LDPE sample. Many of the identified short-chain linear oligomers present industrial, chemical, and cosmetic applications, so they can be present as contaminants. However, their presence can also be due to the partial degradation of LDPE during the recycling process or the solvent extraction. In this respect, the degradation of the recycled LDPE during the solvent extraction process, although undesired, can facilitate the release of contaminants from the polymeric matrix.

The other 291 unidentified features did not meet the necessary criteria to be tentatively identified with a sufficient level of confidence (see Table 1). On the other hand, the used mass range (from 40 to $500 \mathrm{~m} / \mathrm{z}$ ) may have meant that substances with fragment ions above $500 \mathrm{~m} / \mathrm{z}$ were not detected or underestimated. A wider range could be used if allowed by the instrument characteristics.

\subsection{Confirmation with Standards}

In order to validate the proposed methodology, commercially available analytical standards of 10 of the 83 tentatively identified substances were purchased (see Section 2.1), and they were used to confirm their identity and to quantify them. Standard solutions containing the analytes from 20 to $500 \mathrm{ng} \mathrm{mL}^{-1}$ and $200 \mathrm{ng} \mathrm{mL}^{-1}$ of the internal standards were prepared and analyzed with the same conditions (see Section 2.2.2).

The tested compounds were evaluated in terms of the acquired retention time, exact mass, and MS spectrum, between the analyzed LDPE sample and the standards. As an example, the chromatographic base peak and the MS spectrum, acquired in the standard solution and in the analyzed sample, for Butylated hydroxytoluene (BHT) and Tris (2,4-ditert-butylphenyl) phosphite (Irgafos 168) are shown in Figures 2 and 3, respectively.

All of the tested compounds presented a good match between the acquired features in the analyzed LDPE sample and the standards, thus showing that the proposed methodology provided reliable results. It can be noted that a slight drift in retention time was observed due to the elapsed time between the sample analysis and the confirmation with standards. However, this drift did not significantly affect the obtained results.

It should be noted that, although quantification was performed for 10 of the tentatively identified substances, the objective of the present study is not to provide a target quantitative procedure for these or other particular substances, but to provide a reliable methodology that can be used as a screening tool to perform the identification and risk assessment of unknown substances in plastic FCM. In this sense, these 10 analytical standards were selected due to their commercial availability in order to validate the proposed strategy for the tentative identification of unknown substances. 

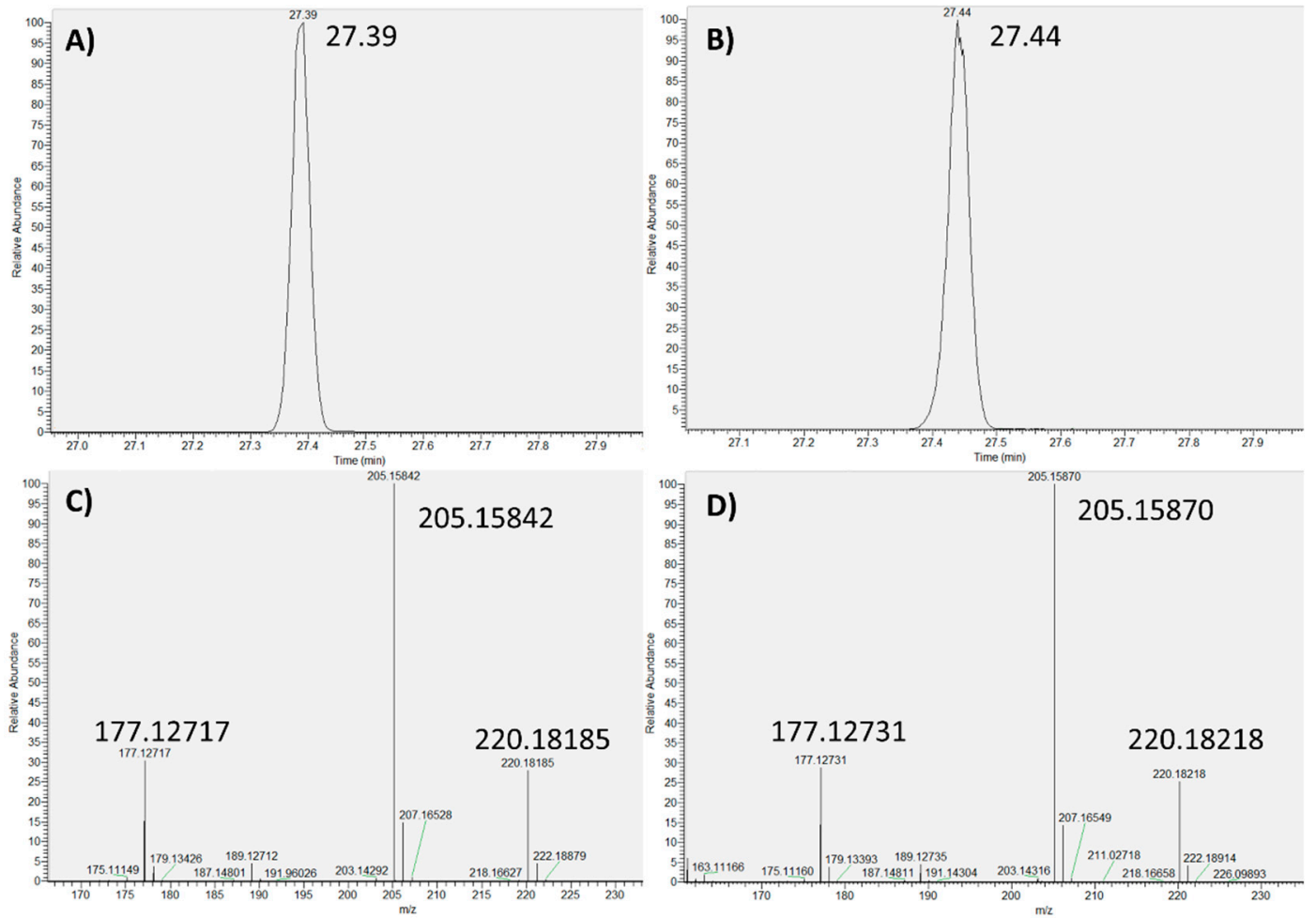

Figure 2. Butylated hydroxytoluene (BHT): (A) Base peak (standard); (B) Base peak (sample); (C) MS spectrum (standard); (D) MS spectrum (sample).
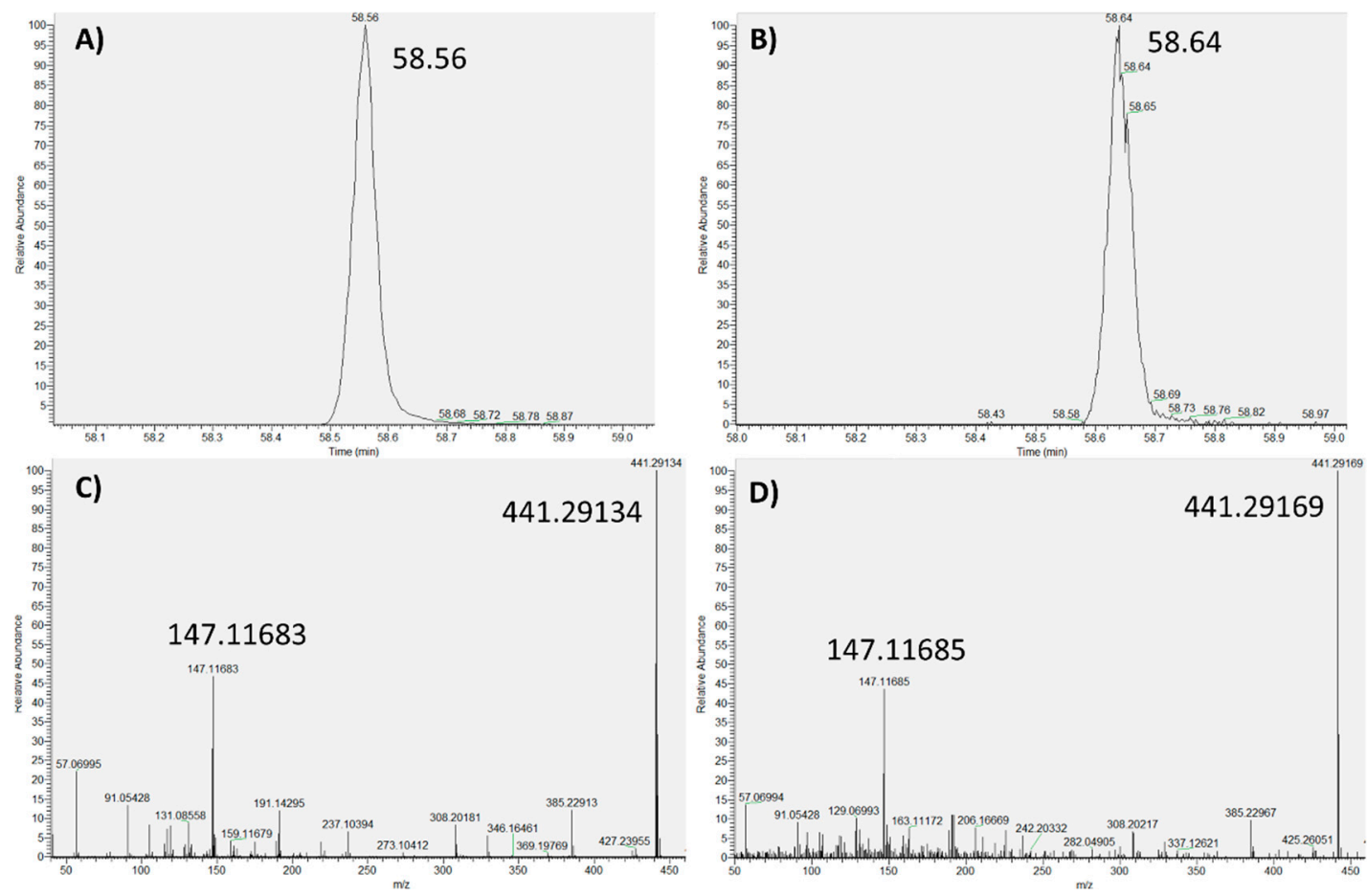

Figure 3. Tris (2,4-di-tert-butylphenyl) phosphite (Irgafos 168): (A) Base peak (standard); (B) Base peak (sample); (C) MS spectrum (standard); (D) MS spectrum (sample). 


\subsection{Risk Assessment of Recycled LDPE}

After the tentative identification of the detected substances by applying the proposed methodology (see Section 2.2), a risk assessment was performed using the TTC approach (see Section 2.3). According to Commission Regulation (EU) No 10/2011 [1], a maximum limit of $0.01 \mathrm{mg} \mathrm{kg}^{-1}$ is established for the migration of NIAS from FCM across a functional barrier, except for substances whose genotoxicity has not been discarded, which should not migrate in levels higher than $0.00015 \mathrm{mg} \mathrm{kg}^{-1}$. In this sense, only the identified substances with an estimated migration over $0.00015 \mathrm{mg} \mathrm{kg}^{-1}$ were considered for the risk assessment. Out of 83 identified substances, only 9 were found at a migration level above $0.01 \mathrm{mg} \mathrm{kg}^{-1}$, and 45 substances were found at a migration level above $0.00015 \mathrm{mg} \mathrm{kg}^{-1}$. Some of the assessed compounds were IAS, according to the abovementioned regulation. In those cases, their specific migration limits (SML) were considered. These results are shown in Table 3.

Table 3. Risk assessment of the identified substances.

\begin{tabular}{|c|c|c|c|c|c|c|}
\hline Compound Name & CAS Number & $\begin{array}{l}\text { Migration } \\
\left(\mathrm{mg} \mathrm{kg}^{-1}\right)^{1}\end{array}$ & $\begin{array}{c}\mathrm{SML} \\
\left(\mathrm{mg} \mathrm{kg}^{-1}\right)^{2}\end{array}$ & $\begin{array}{c}\text { Toxicological } \\
\text { Hazard } \\
\text { (Cramer Class) }^{3} \\
\end{array}$ & $\begin{array}{c}\text { TDI } \\
\text { (mg Person }^{-1} \\
\left.\text { day }^{-1}\right)^{4}\end{array}$ & $\begin{array}{c}\text { EDI } \\
\left(\mathrm{mg} \mathrm{Person}^{-1}\right. \\
\left.\text { day }^{-1}\right)^{5}\end{array}$ \\
\hline Irgafos $168^{*}$ & $31570-04-4$ & $2.0 \pm 0.2$ & - & & & \\
\hline Methyl palmitate & $112-39-0$ & 0.058 & & Low (Class I) & 1.80 & 0.058 \\
\hline Methyl stearate & $112-61-8$ & 0.058 & & Low (Class I) & 1.80 & 0.058 \\
\hline 1,2-Diphenoxyethane & $104-66-5$ & 0.033 & & High (Class III) & 0.09 & 0.033 \\
\hline Octadecane & $593-45-3$ & 0.021 & & Low (Class I) & 1.80 & 0.021 \\
\hline $\begin{array}{l}\text { Bis(2-ethylhexyl) } \\
\text { terephthalate* }\end{array}$ & $6422-86-2$ & $0.020 \pm 0.002$ & 60 & & & \\
\hline Tetracosane & $646-31-1$ & 0.018 & & Low (Class I) & 1.80 & 0.018 \\
\hline Octacosane & $630-02-4$ & 0.013 & & Low (Class I) & 1.80 & 0.013 \\
\hline $\begin{array}{c}\text { Butylated } \\
\text { hydroxytoluene* }\end{array}$ & $128-37-0$ & $0.010 \pm 0.001$ & 3 & & & \\
\hline Hexadecane & $544-76-3$ & 0.009 & & Low (Class I) & 1.80 & 0.009 \\
\hline $\begin{array}{c}\text { Methyl } \\
\text { dehydroabietate }\end{array}$ & $1235-74-1$ & 0.009 & & Low (Class I) & 1.80 & 0.009 \\
\hline Tetraiacontane & $14167-59-0$ & 0.007 & & Low (Class I) & 1.80 & 0.007 \\
\hline Eicosane & $112-95-8$ & 0.005 & & Low (Class I) & 1.80 & 0.005 \\
\hline Benzophenone* & $119-61-9$ & $0.0030 \pm 0.0005$ & 0.6 & & & \\
\hline $\begin{array}{l}\text { Bis(2-ethylhexyl) } \\
\text { phthalate * }\end{array}$ & $117-81-7$ & $0.0025 \pm 0.0005$ & 1.5 & & & \\
\hline $\begin{array}{l}\text { 2,6-Di-tert- } \\
\text { butylphenol }\end{array}$ & $128-39-2$ & 0.002 & & $\begin{array}{l}\text { Intermediate } \\
\text { (Class II) }\end{array}$ & 0.54 & 0.002 \\
\hline $\begin{array}{c}\mathrm{N}, \mathrm{N}- \\
\text { Dimethylpalmitylamine }\end{array}$ & $112-69-6$ & 0.002 & & Low (Class I) & 1.80 & 0.002 \\
\hline $\begin{array}{c}\text { Octadecyl } \\
\text { trifluoroacetate }\end{array}$ & 79392-43-1 & 0.0014 & & High (Class III) & 0.09 & 0.0014 \\
\hline $\begin{array}{c}2,6- \\
\text { Diisopropylnaphthalene }\end{array}$ & $24157-81-1$ & 0.0014 & & High (Class III) & 0.09 & 0.0014 \\
\hline $\begin{array}{l}\text { Diisobutyl phthalate } \\
\text { Irganox } 1076^{*}\end{array}$ & $\begin{array}{c}84-69-5 \\
2082-79-3\end{array}$ & $\begin{array}{c}0.0014 \pm 0.0002 \\
0.0013\end{array}$ & 6 & Low (Class I) & 1.80 & 0.0014 \\
\hline $\begin{array}{l}\text { 7,9-Di-tert-butyl-1- } \\
\text { oxaspiro(4,5)deca-6,9- } \\
\text { diene-2,8-dione }\end{array}$ & $82304-66-3$ & 0.0010 & & High (Class III) & 0.09 & 0.0010 \\
\hline Methyl linolelaidate & $2566-97-4$ & 0.0009 & & Low (Class I) & 1.80 & 0.0009 \\
\hline 1-Tetracosene & $10192-32-2$ & 0.0009 & & Low (Class I) & 1.80 & 0.0009 \\
\hline $\begin{array}{l}\text { 2,4-Di-tert- } \\
\text { pentylphenol }\end{array}$ & $120-95-6$ & 0.0008 & & Low (Class I) & 1.80 & 0.0008 \\
\hline Methyl elaidate & $1937-62-8$ & 0.0007 & & Low (Class I) & 1.80 & 0.0007 \\
\hline Nonadecanol & $1454-84-8$ & 0.0007 & & Low (Class I) & 1.80 & 0.0007 \\
\hline Squalene & $111-02-4$ & 0.0007 & & Low (Class I) & 1.80 & 0.0007 \\
\hline $\begin{array}{c}\text { 3,5-Di-tert-butyl-4- } \\
\text { hydroxybenzaldehyde }\end{array}$ & $1620-98-0$ & 0.0005 & & $\begin{array}{l}\text { Intermediate } \\
\text { (Class II) }\end{array}$ & 0.54 & 0.0005 \\
\hline $\begin{array}{l}\text { 2,4-Di-tert- } \\
\text { butylphenol }\end{array}$ & $96-76-4$ & 0.0005 & & Low (Class I) & 1.80 & 0.0005 \\
\hline $\begin{array}{l}\text { 2,6-Di-tert-butyl-1,4- } \\
\text { benzoquinone }\end{array}$ & $719-22-2$ & 0.0005 & & $\begin{array}{l}\text { Intermediate } \\
\quad(\text { Class II) }\end{array}$ & 0.54 & 0.0005 \\
\hline $\begin{array}{l}\text { Bis(2-ethylhexyl) } \\
\text { adipate* }\end{array}$ & $103-23-1$ & $0.0005 \pm 0.0001$ & 18 & & & \\
\hline Galaxolide & $1222-05-5$ & 0.0005 & & High (Class III) & 0.09 & 0.0005 \\
\hline
\end{tabular}


Table 3. Cont

\begin{tabular}{|c|c|c|c|c|c|c|}
\hline Compound Name & CAS Number & $\begin{array}{l}\text { Migration } \\
\left(\mathrm{mg} \mathrm{kg}^{-1}\right)^{1}\end{array}$ & $\begin{array}{c}\text { SML } \\
\left(\mathrm{mg} \mathrm{kg}^{-1}\right)^{2}\end{array}$ & $\begin{array}{c}\text { Toxicological } \\
\text { Hazard } \\
\text { (Cramer Class) }^{3}\end{array}$ & $\begin{array}{c}\text { TDI } \\
\text { (mg Person }^{-1} \\
\left.\text { day }^{-1}\right)^{4}\end{array}$ & $\begin{array}{c}\text { EDI } \\
\underset{\left.\text { day }^{-1}\right)^{5}}{(m g \text { Person }}\end{array}$ \\
\hline 1-Chlorohexadecane & $4860-03-1$ & 0.0004 & & High (Class III) & 0.09 & 0.0004 \\
\hline 1-Hexadecene & $629-73-2$ & 0.0003 & & Low (Class I) & 1.80 & 0.0003 \\
\hline Hexadecyl palmitate & $540-10-3$ & 0.0003 & & Low (Class I) & 1.80 & 0.0003 \\
\hline Isopropyl myristate & $110-27-0$ & 0.0003 & & Low (Class I) & 1.80 & 0.0003 \\
\hline $\begin{array}{l}\text { Hexadecyl } \\
\text { trifluoroacetate }\end{array}$ & $6222-03-3$ & 0.0003 & & High (Class III) & 0.09 & 0.0003 \\
\hline Methyl abietate & $127-25-3$ & 0.0003 & & High (Class III) & 0.09 & 0.0003 \\
\hline $\begin{array}{c}2,6,10,15 \text {-Tetramethyl } \\
\text { heptadecane }\end{array}$ & $54833-48-6$ & 0.0003 & & Low (Class I) & 1.80 & 0.0003 \\
\hline Butyl palmitate * & $111-06-8$ & 0.0002 & - & & & \\
\hline 11-Methyltricosane & $27538-41-6$ & 0.0002 & & Low (Class I) & 1.80 & 0.0002 \\
\hline Hexadecyl acetate & $629-70-9$ & 0.0002 & & Low (Class I) & 1.80 & 0.0002 \\
\hline 3-Nonenol & $10340-23-5$ & 0.00018 & & Low (Class I) & 1.80 & 0.00018 \\
\hline Metilox & $6386-38-5$ & 0.00017 & & $\begin{array}{l}\text { Intermediate } \\
\text { (Class II) }\end{array}$ & 0.54 & 0.00017 \\
\hline
\end{tabular}

${ }^{1}$ Migration $\left(\mathrm{mg} \mathrm{kg}^{-1}\right)$ estimated from the average response factor of internal standards or determined with analytical standards. ${ }^{2}$ Specific migration limit (SML) according to Commission Regulation (EU) No 10/2011 [1]. ${ }^{3}$ Cramer class of toxicological hazard calculated using Toxtree software [33]. ${ }^{4}$ Tolerable daily intake (TDI) value depending on toxicological hazard (Cramer class). ${ }^{5}$ Estimated daily intake (EDI) value calculated from Migration ( $\mathrm{mg} \mathrm{kg}^{-1}$ ) according to current European default assumption [39]. * Authorized substances (IAS) according to Commission Regulation (EU) No 10/2011 [1].

As can be seen, all of the identified NIAS presented an estimated daily intake (EDI) lower than their tolerable daily intake (TDI), according to their toxicological hazard (Cramer class). Moreover, all of the identified IAS presented a migration level lower than their SML. Therefore, it can be concluded that there was no risk associated with the release of the identified substances from the recycled LDPE film. Moreover, it would be necessary to perform further studies in order to tentatively identify and to evaluate the risk associated with the release of the 291 unidentified substances detected in the analyzed LDPE sample, which could present potential genotoxicity. Likewise, toxicity studies related with the unidentified substances and mixture toxicity (cocktail effects) would be necessary.

Although substance migration was not performed using food simulants, according to Commission Regulation (EU) No 10/2011 [1], the methodology presented in this paper constitutes a faster and reliable procedure to perform a first screening approach to assess the safety of plastic FCM after direct solvent extraction.

\section{Conclusions}

In this work, a fast and automatic strategy has been developed for the non-target analysis of plastic materials and articles intended to come into contact with food (FCM) by GCQ-Orbitrap HRMS, including tentative identification of unknown substances (IAS/NIAS) and risk assessment by using the threshold of toxicological concern (TTC) approach.

As a proof-of-concept demonstration, the proposed methodology was applied to post-consumer recycled LDPE film, which could be used as FCM, obtaining 374 annotated features, of which 83 were tentatively identified after examination of the identification criteria. Moreover, 10 of these were successfully confirmed with commercial analytical standards, thus showing that the proposed methodology provided reliable results. Most of the identified compounds were plastic additives, such as plasticizers, used in different plastic applications. Moreover, oligomers of LDPE, metabolites, substances with industrial, chemical, and cosmetic applications, and other plastic-related substances were also identified. After performing the tentative identification, a risk assessment of the analyzed LDPE was carried out, showing that the release of the identified substances did not represent a safety risk. However, complementary studies related with the toxicity of the unidentified substances and the potential mixture toxicity (cocktail effects) should be conducted in parallel using bioassays.

The proposed analytical methodology, including solvent extraction, GC-HRMS analysis, tentative identification, and risk assessment constitutes a fast and automatic approach 
that can be applied for the non-target analysis of unknown substances (IAS/NIAS) of different plastic FCM, showing its great utility and versatility.

Author Contributions: Conceptualization, P.M., V.Y., A.P. and C.C.; methodology, P.M. and V.Y.; validation, P.M. and C.C.; formal analysis, P.M. and C.C.; investigation, P.M. and V.Y.; resources, V.Y., A.P. and C.C.; data curation, P.M., V.Y. and C.C.; writing-original draft preparation, P.M.; writing-review and editing, P.M., V.Y. and C.C.; visualization, V.Y. and C.C; supervision, V.Y. and C.C.; project administration, V.Y., A.P. and C.C.; funding acquisition, V.Y., A.P. and C.C. All authors have read and agreed to the published version of the manuscript.

Funding: This research was developed in the framework of a collaboration agreement between FISABIO-Public Health (Valencia, Spain) and Cadel Deinking S.L (Sant Vicent del Raspeig, Spain). The study was co-funded by the European Union through the European Regional Development Funds (ERDF) Operational Programme of the Valencian Region (2014-2020). The APC was funded by FISABIO-Public Health (Valencia, Spain).

Institutional Review Board Statement: Not applicable.

Informed Consent Statement: Not applicable.

Data Availability Statement: Data are available upon reasonable request from the corresponding author.

Conflicts of Interest: The authors declare no conflict of interest.

\section{References}

1. Regulation, C. No 10/2011 of 14 January 2011 on Plastic Materials and Articles Intended to Come into Contact with Food (and Its Successive Amendments). Available online: http://data.europa.eu/eli/reg/2011/10/2020-09-23 (accessed on 20 September 2021).

2. International Life Science Institute (ILSI) Europe. Guidance on Best Practices on the Risk Assessment of Non-Intentionally Added Substances (NIAS) in Food Contact Materials and Articles; ILSI Europe: Brussels, Belgium, 2015.

3. Aznar, M.; Alfaro, P.; Nerín, C.; Jones, E.; Riches, E. Progress in mass spectrometry for the analysis of set-off phenomena in plastic food packaging materials. J. Chromatogr. A 2016, 1453, 124-133. [CrossRef] [PubMed]

4. Yusà, V.; López, A.; Dualde, P.; Pardo, O.; Fochi, I.; Pineda, A.; Coscolla, C. Analysis of unknowns in recycled LDPE plastic by LC-Orbitrap Tribrid HRMS using MS ${ }^{3}$ with an intelligent data acquisition mode. Microchem. J. 2020, 158, 105256. [CrossRef]

5. Gallart-Ayala, H.; Nunez, O.; Lucci, P. Recent advances in LC-MS analysis of food-packaging contaminants. TrAC Trends Anal. Chem. 2013, 42, 99-124. [CrossRef]

6. Hoppe, M.; de Voogt, P.; Franz, R. Identification and quantification of oligomers as potential migrants in plastics food contact materials with a focus in polycondensates-A review. Trends Food Sci. Technol. 2016, 50, 118-130. [CrossRef]

7. Sanchis, Y.; Yusà, V.; Coscollà, C. Analytical strategies for organic food packaging contaminants. J. Chromatogr. A 2017, 1490, 22-46. [CrossRef]

8. Martínez-Bueno, M.J.; Gómez Ramos, M.J.; Bauer, A.; Fernández-Alba, A.R. An overview of non-targeted screening strategies based on high resolution accurate mass spectrometry for the identification of migrants coming from plastic food packaging materials. TrAC Trends Anal. Chem. 2019, 110, 191-203. [CrossRef]

9. Wrona, M.; Nerín, C. Analytical approaches for analysis of safety of modern food packaging: A review. Molecules 2020, 25, 752. [CrossRef]

10. Ouyang, X.; Lu, Z.; Hu, Y.; Xie, Z.; Li, G. Research progress on sample pretreatment methods for migrating substances from food contact materials. J. Sep. Sci. 2021, 44, 879-894. [CrossRef] [PubMed]

11. Martínez-Bueno, M.J.; Cimmino, S.; Silvestre, C.; Tadeo, J.L.; García-Valcárcel, A.I.; Fernández-Alba, A.R.; Hernando, M.D. Characterization of non-intentionally added substances (NIAS) and zinc oxide nanoparticle release from evaluation of new antimicrobial food contact materials by both LC-QTOF-MS, GC-QTOF-MS and ICP-MS. Anal. Methods 2016, 8, 7209-7216. [CrossRef]

12. Canellas, E.; Vera, P.; Nerín, C. UPLC-ESI-Q-TOF-MS ${ }^{\mathrm{E}}$ and GC-MS identification and quantification of non-intentionally added substances coming from biodegradable food packaging. Anal. Bioanal. Chem. 2015, 407, 6781-6790. [CrossRef] [PubMed]

13. Liu, A.; Qu, G.; Zhang, C.; Gao, Y.; Shi, J.; Du, Y.; Jiang, G. Identification of two novel brominated contaminants in water samples by ultra-high performance liquid chromatography-Orbitrap Fusion Tribrid mass spectrometer. J. Chromatogr. A 2015, 1377, 92-99. [CrossRef]

14. Wu, Y.; Gao, S.; Liu, Z.; Zhao, J.; Ji, B.; Zheng, X.; Yu, Z. The quantification of chlorinated paraffins in environmental samples by ultra-high-performance liquid chromatography coupled with Orbitrap Fusion Tribrid mass spectrometry. J. Chromatogr. A 2019, 1593, 102-109. [CrossRef] 
15. Yusà, V.; López, A.; Dualde, P.; Pardo, O.; Fochi, I.; Miralles, P.; Coscollà, C. Identification of 24 unknown substances (IAS/NIAS) from food contact polycarbonate by LC-Orbitrap Tribrid HRMS-DDMS ${ }^{3}$ : Safety assessment. Int. J. Anal. Chem. 2021, 2021, 6654611. [CrossRef]

16. Miralles, P.; López, A.; Dualde, P.; Coscollà, C.; Yusà, V. LC-Orbitrap Tribrid high-resolution MS using data dependent-tandem mass spectrometry with triple stage fragmentation as a screening tool to perform identification and risk assessment of unknown substances in food contact epoxy resin. J. Sep. Sci. 2021, 44, 3020-3030. [CrossRef]

17. Horodytska, O.; Cabanes, A.; Fullana, A. Non-intentionally added substances (NIAS) in recycled plastics. Chemosphere 2020, 251, 126373. [CrossRef] [PubMed]

18. Canellas, E.; Vera, P.; Nerín, C. Atmospheric pressure gas chromatography coupled to quadrupole-time of flight mass spectrometry as a tool for identification of volatile migrants from autoadhesive labels used for direct food contact. J. Mass Spectrom. 2014, 49, 1181-1190. [CrossRef]

19. Martínez-Bueno, M.J.; Hernando, M.D.; Uclés, S.; Rajski, L.; Cimmino, S.; Fernández-Alba, A.R. Identification of non-intentionally added substances in food packaging nano films by gas and liquid chromatography coupled to orbitrap mass spectrometry. Talanta 2017, 172, 68-77. [CrossRef] [PubMed]

20. García Ibarra, V.; Rodríguez Bernaldo de Quirós, A.; Paseiro Losada, P.; Sendón, R. Non-target analysis of intentionally and non-intentionally added substances from plastic packaging materials and their migration into food simulants. Food Packag. Shelf Life 2019, 21, 100325. [CrossRef]

21. National Institute of Standards and Technology (NIST). NIST/EPA/NIH Mass Spectral Library (NIST 20); NIST: Gaithesburg, MD, USA, 2020.

22. Biedermann, M.; Grob, K. Comprehensive two-dimensional gas chromatography for characterizing mineral oils in foods and distinguishing them from synthetic hydrocarbons. J. Chromatogr. A 2015, 1375, 146-153. [CrossRef] [PubMed]

23. Franz, R.; Welle, F. Contamination levels in recollected PET bottles from non-food applications and their impact on the safety of recycled PET for food contact. Molecules 2020, 25, 4998. [CrossRef]

24. Van Velzen, E.U.T.; Brouwer, M.T.; Stärker, C.; Welle, F. Effect of recycled content and rPET quality of the properties of PET bottles, part II: Migration. Packag. Technol. Sci. 2020, 33, 359-371. [CrossRef]

25. Omer, E.; Bichon, E.; Hutinet, S.; Royer, A.; Monteau, F.; Germon, H.; Hill, P.; Remaud, G.; Dervilly-Pinel, G.; Cariou, R.; et al. Toward the characterisation of non-intentionally added substances migrating from polyester-polyurethane lacquers by comprehensive gas chromatography-mass spectrometry technologies. J. Chromatogr. A 2019, 1601, 327-334. [CrossRef] [PubMed]

26. Song, X.; Wrona, M.; Nerin, C.; Lin, Q.; Zhong, H. Volatile non-intentionally added substances (NIAS) identified in recycled expanded polystyrene containers and their migration into food simulants. Food Packag. Shelf Life 2019, 20, 100318. [CrossRef]

27. Canellas, E.; Vera, P.; Domeño, C.; Alfaro, P.; Nerín, C. Atmospheric pressure gas chromatography coupled to quadrupole-time of flight mass spectrometry as a powerful tool for identification of non-intentionally added substances in acrylic adhesives used in food packaging materials. J. Chromatogr. A 2012, 1235, 141-148. [CrossRef]

28. Ubeda, S.; Aznar, M.; Nerín, C. Determination of volatile compounds and their sensory impact in a biopolymer based on polylactic acid (PLA) and polyester. Food Chem. 2019, 294, 171-178. [CrossRef] [PubMed]

29. Onghena, M.; van Hoeck, E.; van Loco, J.; Ibáñez, M.; Cherta, L.; Portolés, T.; Pitarch, E.; Hernández, F.; Lemière, F.; Covaci, A. Identification of substances migrating from plastic baby bottles using a combination of low-resolution and high-resolution mass spectrometric analysers coupled to gas and liquid chromatography. J. Mass Spectrom. 2015, 50, 1234-1244. [CrossRef] [PubMed]

30. EFSA Scientific Committee. Scientific opinion on exploring options for providing advice about possible human health risk based on the concept of threshold of toxicological concern (TTC). EFSA J. 2012, 10, 2750.

31. Canellas, E.; Vera, P.; Nerin, C. Migration assessment and the 'threshold of toxicological concern' applied to the safe design of an acrylic adhesive for food-contact laminates. Food Addit. Contam. Part A Chem. Anal. Control Expo. Risk Assess. 2017, 34, 1721-1729. [CrossRef] [PubMed]

32. Pieke, E.N.; Granby, K.; Teste, B.; Smedsgaard, J.; Rivière, G. Prioritization before risk assessment: The viability of uncertain data on food contact materials. Regul. Toxicol. Pharmacol. 2018, 97, 134-143. [CrossRef]

33. Patlewicz, G.; Jeliazkova, N.; Safford, R.J.; Worth, A.P.; Aleksiev, B. An evaluation of the implementation of the Cramer classification scheme in the Toxtree software. SAR QSAR Environ. Res. 2008, 19, 495-524. [CrossRef]

34. Matthews, C.; Moran, F.; Jaiswal, A.K. A review on European Union's strategy for plastics in a circular economy and its impact on food safety. J. Clean. Prod. 2021, 283, 125263. [CrossRef]

35. Plastic Recyclers Europe (PRE). Flexible Polyethylene Recycling in Europe: Accelerating the Transition towards Circular Economy. Available online: https://www.pac.gr/bcm/uploads/flexible-pe-recycling-in-europe_june-2019.pdf (accessed on 20 September 2021).

36. Commission Regulation. (EC) No 282/2008 of 27 March 2008 on Recycled Plastic Materials and Articles Intended to Come into Contact with Foods and Amending Regulation (EC) No 2003/2006 (and its Successive Amendments). Available online: http:/ / data.europa.eu/eli/reg/2008/282/2015-10-26 (accessed on 20 September 2021).

37. Fullana Font, A.; Lozano Morzillo, A. Method for Removing Ink Printed on Plastic Films. ES2427019A1, 28 october 2013. 
38. Compound Discoverer 3.2 Software. Thermo Fisher Scientific: Waltham, MA, USA, 2021. Available online: https: //www.thermofisher.com/es/es/home/industrial/mass-spectrometry/liquid-chromatography-mass-spectrometry-lcms/lc-ms-software/multi-omics-data-analysis/compound-discoverer-software.html (accessed on 20 September 2021).

39. Food Contact Additives (FCA). Risk Assessment of Non-Listed Substances (NLS) and Non-Intentionally Added Substances (NIAS) under the Requirements of Article 3 of the Framework Regulation (EC) 1935/2004, Version 3.0. 2020. Available online: https:/ / fca.cefic.org/wp-content/uploads/2021/02/FCA_Risk_Assessment_Guidelines_v30-1.pdf (accessed on 20 September 2021). 